\title{
Research on the Significance of "The Unity of Knowing and Doing" to the Overseas Practice of Teaching Chinese to Speakers of Other Languages
}

\author{
Lin Zhang \\ College of Foreign Studies, Guilin University of Electronic Technology, Guilin, Guangxi, 541004, \\ China
}

zhangzhang202@126.com

\begin{abstract}
Keywords: "The unity of knowing and doing", overseas teaching practice, teaching Chinese to speakers of other languages.
\end{abstract}

\begin{abstract}
Through survey of trainees' overseas practice condition of teaching Chinese to speakers of other languages in Guilin University of Electronic Technology of Chinese, this article analyzes the gain and loss of achieving students' "the unity of knowing and doing" in overseas practice from several angles, discusses the importance of " the unity of knowing and doing" in overseas practice, and proposes how to solve disjointed problem of "knowing" and "doing" in students ' training.
\end{abstract}

\section{Introduction}

"The unity of knowing and doing" is vital for the growth of modern teachers, and this idea is no exception for the teachers' training in teaching Chinese as a foreign language, as a result, we take overseas practice as a breakthrough point, and use survey methods to explore the importance of "the unity of knowing and doing" in overseas practice. "Knowing" of "the unity of knowing and doing" are knowledge structures which trainees have built up while growing up, including the learned knowledge and experience and so on, but "knowing" discussed in this article are mainly learning theory knowledge and professional skills that trainees study in university. And "doing" are mainly the teaching behaviors of training, for example teaching methods, teaching language and other teaching behaviors [1-3].

The unity of "knowing" and "doing" is that the trainees can apply the learned knowledge in the teaching practice, and find their shortcomings of knowledge reserve of classroom management in the process of teaching practice, and timely make up the deficiency, and realize "the unity of knowing and doing" $[4,5]$.

\section{Preliminary Results of Survey of Overseas Trainees}

The 2013 grade 28 students of teaching Chinese to speakers of other languages in College of Foreign Studies of Guilin University of Electronic Technology have carried out the questionnaire survey; investigated students are 28 persons totally, including 4 boys and 24 girls, 28 persons have conducted overseas teaching practice at Thai Nguyen University in Vietnam, the practice period is one and a half months.

Trainees conducted overseas practice for over one month in the non-target language environment, learned to apply learned professional knowledge in the classroom of teaching Chinese to speakers of other languages, and improve their teaching ability and the comprehensive quality. According to the survey data, $98 \%$ of trainees enjoy the role of teachers in the foreign language classroom, and think that overseas practice can help improve their professional quality. At the same time, we also found that trainees have different performance in overseas practice.

According to statistics, $60 \%$ of trainees can combine theoretical knowledge with practical teaching well in overseas teaching, such as teaching aspect, they can give feedback to students who answer questions in time, and can adjust the language speed and classroom language of the class according to the basic level of Vietnamese students. 
Another 40 percent of trainees' lack "the unity of knowing and doing" ability in overseas teaching, such as lacking skills of mobilizing atmosphere classroom atmosphere in classroom management. Some trainees' Putonghua is still not standard, and some trainees have "is that so" and "eh" in their lectures, and their language expression ability needs to be improved. Although the trainees have a certain knowledge reserve, it is difficult to apply it skillfully to teaching. The frequency of these phenomena at the beginning of the overseas teaching is high, it shows that most of the trainees have disjointed problem of "knowing" and "doing", namely "knowing" and "doing" alienate from each other (Figure 1).

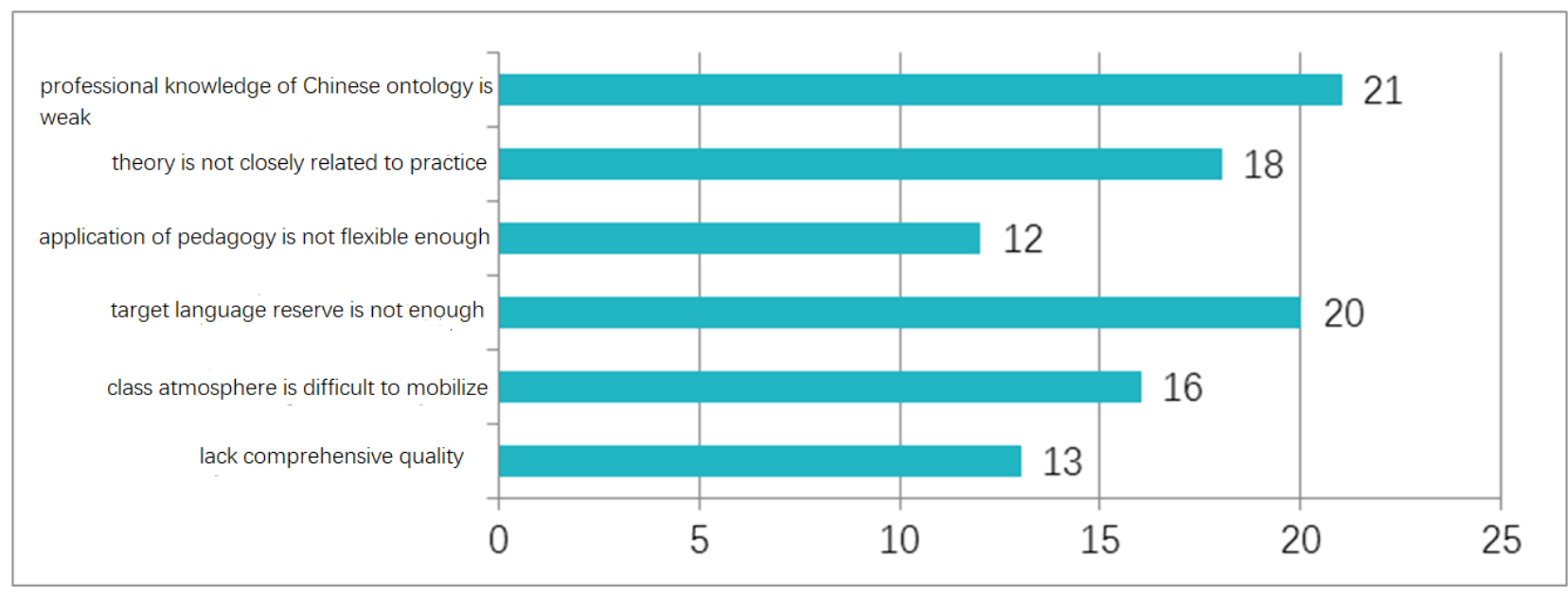

Figure.1 Statistical diagram of survey results the trainee's own deficiency

\section{Research on the Overseas Trainees' Ability to Use Professional Knowledge}

The classroom of teaching Chinese as a foreign language is mainly teaching the basic knowledge of phonetics and grammar, and the trainees must firmly grasp the ontology knowledge of Chinese. According to the survey, 30 percent of trainees explain an easy new word with some more difficult words, causing the students to listen confused, and the teaching effect is greatly reduced. According to the interview, we understand that the above situation is because the trainees are too impatient in class; want to finish explaining the new word in a hurry and speak too fast, meanwhile also ignore the Vietnamese students' Chinese level, and cause their words used in explanation are too difficult.

45 percent of the trainees experienced awkward situations where the new words are not clearly explained. For some seemingly simple words and grammar, trainees thought that the students had learned when preparing lessons, wanted to skim over in class one, as a result, the trainees are difficult to explain when students ask questions.

65 percent of trainees don't know how to correct when Vietnamese students have phonetic error. According to the survey, $60 \%$ of the classes in the overseas practice are advanced class, and Vietnamese students have studied Chinese for three years, who have a certain Chinese foundation. We found that although the trainees study Vietnamese for one semester in school, but applying the Vietnamese also has certain difficulty in teaching Chinese as a foreign language class, so most of the trainees are rarely used Vietnamese in class, if you want to explain a harder word, trainees mostly choose to use body language or English to explain, and most of the Vietnamese students' English is not good, so it is difficult for trainees to correct their students in class. In the aspect of voice error correction, such as "qie", the vowel of this word is /i $\varepsilon /$, while Vietnamese students will speak pronounce /i $\varepsilon \mathrm{r} /, 80 \%$ of trainees will correct pronunciation by repeated reading, and then let the students repeat. The correction methods of the trainees are relatively simple, and do not connect the ontology knowledge of Chinese to correct from the pronunciation principle. In the aspect of grammar error correction, $71 \%$ of trainees generally cite examples, guide the students to find application rules, and let the students do the corresponding grammatical subject to practice, it is very rare to compare and explain grammar one by one. 
These situations above reflect that master degrees for target language of $60 \%$ of trainees are not enough, they are not proficient in the use of ontology knowledge of Chinese, some trainees ' knowledge of pronunciation and vocabulary teaching is weak, namely the trainees' "knowing" reserve is not enough and difficult to face classroom environment changes. It is difficult to apply the learned knowledge to the actual teaching, so that the "knowing" and "doing" are disjointed.

We know that the 2013 grade teaching Chinese to speakers of other languages opened the course "Modern Chinese" in the first and second year at university, the third semester opened the "Introduction to Linguistics" course, these two courses are undergraduate important course of teaching Chinese to speakers of other languages, although the course schedule are arranged enough, trainees still lack ontology knowledge of Chinese. According to the survey, it is found that most of the trainees' learning motivations at university are to pass the exam, so most trainees only review the learned knowledge before the examination, this learning process, which lacks autonomy, is naturally difficult to learn true knowledge. On the other hand, although the trainees achieved high marks in exams, there are lack of opportunities to use this professional knowledge on university campus, it is difficult to test the teaching ability for self, so the weakness of trainees is also hard to find, and overseas practice is a touchstone which test whether trainees can proficiently use the professional knowledge or not.

\section{Research on Overseas Trainees' Feedback Consciousness and Classroom Management Ability}

In the "doing" aspect, the simplest embodiment is the timely feedback consciousness and the standard reward system in the classroom. For trainees, the "doing" also includes the blackboard-writing standard, mastery of mandarin, classroom management ability and teaching reflection ability and so on.

Teachers' feedback plays a very important role in the classroom, especially in the classroom of teaching Chinese to speakers of other languages, answering the affirmative words to students' correct answers, which helps to enhance classroom interaction and promote communication between teachers and students. According to the survey, $90 \%$ of the trainees have a strong feedback sense, after students answer the questions, they respond to the "good and very good" feedback for students, so that the students who answer questions will feel a sense of achievement, and will also stimulate the other students' enthusiasm and adjust the classroom atmosphere. In addition, most of the trainees prepare some Chinese knot with Chinese characteristics for Vietnamese students, which is a reward for students who answer questions positively or perform well in class. This produces a positive impact on the subsequent teaching, students also listen to the teacher in class more attentively, and trainees also enjoy class of teaching Chinese to speakers of other languages and make classroom teaching more successful.

However, although trainees perform well in classroom teaching, there are some problems in classroom management. $80 \%$ of trainees think that it is difficult to adjust the classroom atmosphere, for example the Zhou found that the Vietnamese students are silent in the writing class, do not love to participate in class discussion, and then produce negative emotions, and doubt their teaching ability.

After investigation, we found the main are the following reasons: one is although some Vietnamese students in advanced class, but Chinese foundation is not good, if the trainees' speed is too fast in class, students is difficult to keep up with the trainees' class schedule; second, the class taught by trainees, $95 \%$ are women, while Vietnamese girl shy, not too love to express them, so few students answer questions in class, cause trainees felt the classroom is quiet and lack vitality, and it is difficult to continue teaching.

The professional teachers suggested that prizes can be used to mobilize students' enthusiasm. For example, for students' problems, when learning "Go Shopping" lesson, some trainees prepared small gifts as rewards, carried out situational teaching in the classroom, lets the students perform onstage how to use the new words in the text to make a sentence for shopping, the students' spirits are high, 
contend for participating in class, atmosphere is warm. The teachers pointed out that after the students answered, trainees had better repeat the student's answer, so that the rest of the students could understand whether the answer is correct. Therefore, trainees should work harder during the preparation of lessons, prepare questions according to the grammar points in the text, and then ask questions in the classroom from the easy and difficult order. In this way, the interaction between students and students is guaranteed, and students are given the opportunity to raise their hands to speak, secondly, we can have a general understanding for the students' foundation, and make proper adjustments for the course content, so make it more suitable for the students. In the later teaching, when the trainees encounter the above problems again, the handling way becomes more mature, and the control of the classroom becomes more and more proficient.

\section{Research on the Emotional State of Overseas Trainees.}

According to the survey, it is found that $82 \%$ of the trainees had produced anxiety in the teaching, the main reasons are: self-teaching ability is unconfident, the teachers' professional identity is not strong enough, does not adapt to overseas environment and influence of various factors. In overseas practice, trainees said if they perform passionately in class, but the students are listless under the platform, lack of enthusiasm in class leads to awkward silence, then the trainees' class emotion and teaching enthusiasm will be affected, and then began to doubt their teaching ability (Figure 2).

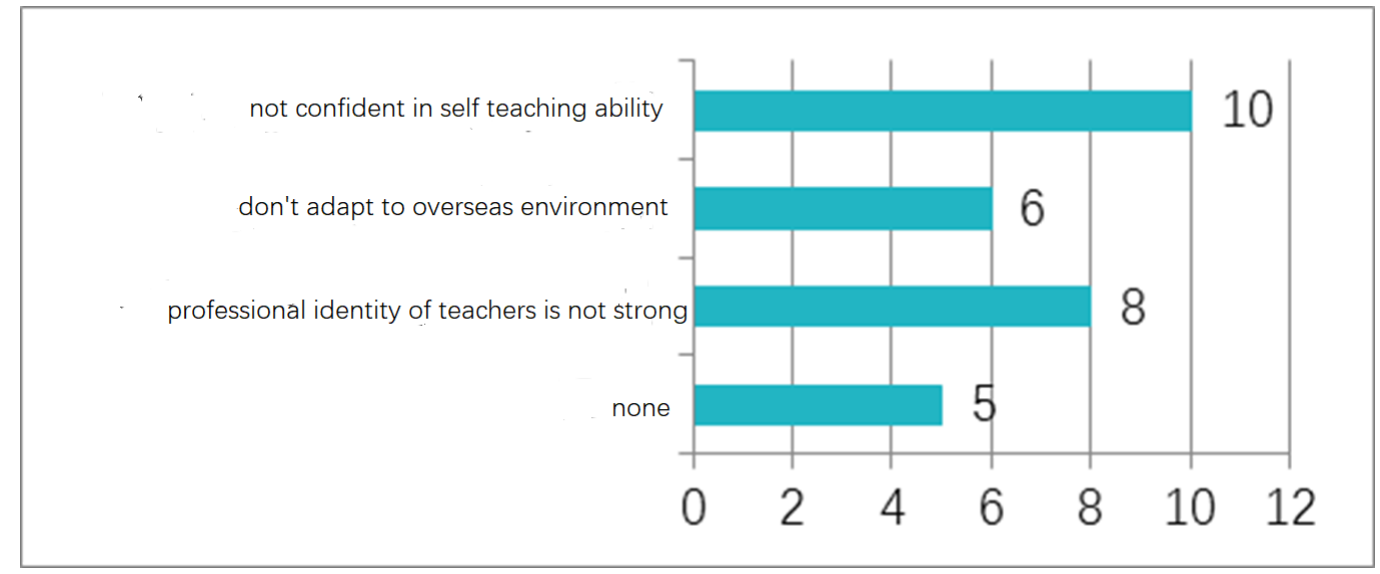

Figure. 2 investigation on anxious psychology of overseas practice students

Trainees' course arrangement are generally two classes per week in the overseas practice, the other time need to listen to the other members' class, they need to prepare lessons, make courseware and organize students' after-school activities in normal times, in addition, the living environment abroad is different from home, in more than one month overseas practice, 29\% of trainees said that they don't have a high sense of professionalism for teachers, the freshness that trainees just come into contact with overseas teaching classes has gradually disappeared, and have a certain sense of tired of teaching, and impact on teaching activities. "Attitude decides everything", these boredom psychologies cause trainees lack proper attitude in teaching, and it is shown as follows: the attitude of preparing lessons is not serious, the language and tone of class lack fluctuation, and t lack interaction with students, and result in the lack of vitality in classroom.

Although 35 percent of trainees have already had some knowledge and abilities, and they are not confident enough in class. For example, trainees feel uncomfortable in class, there is a lot of "um, well" pet phrase in class,", or, they often like to stare at the teaching cases in the class, lack eye contact with students, the existence of these anxiety, on the one hand, the reason is that part of the trainees are introverted, lack experience to speak in large occasion, on the other hand, because the trainees are not confident to self-ability, and they have not converted their roles from students to teachers of teaching Chinese to speakers of other languages.

Although the above are only the problems part trainees, it also reflects that this major in emotion needs to strengthen the training. Now that trainees go to the platform of Chinese as a foreign language 
and teach Chinese knowledge and culture abroad, trainees should strengthen professional identity and sense of responsibility, learn to manage their emotions and ensure orderly teaching management.

\section{Promote the Realization of " the Unity of Knowing and Doing" in a Reasonable and Effective Way}

The training goal of teaching Chinese to speakers of other languages undergraduate is to train applied specialized talents which can engage in Chinese teaching in various schools both at home and abroad, the students in teaching Chinese to speakers of other languages should have professional skills which the Chinese as a second language teaching. The quality of Chinese teachers is mainly composed of knowledge structure, ability structure and ideological and psychological quality. As a teaching Chinese to speakers of other languages teachers, they must first have a solid Chinese language and so on, and are familiar with the basic knowledge of modern Chinese phonetics, vocabulary, and grammar and writing, in addition, they should have the knowledge of psychology education and so on. The course arrangements of teaching Chinese to speakers of other languages are "Modern Chinese", " Introduction to Chinese Culture ", "Teaching Method of Teaching Chinese to Speakers of Other Languages" and other theoretical courses, the problems are easy to appear that students "attach importance to theory and despise practice", therefore, developing overseas practice is an opportunity which test trainees use specialized knowledge ability, and it is the touchstone which test whether the trainees can achieve "knowing and doing".

As an overseas trainee, one should not only master some professional theory and teaching basic skills, but also improve own comprehensive quality. No matter the teaching practice organized by the school, simulation teaching, or participate in the campus debate, speech contest, student union, community and other activities, it has a positive effect on the promotion of the comprehensive quality of self, it also can make the trainees in various teaching environment, apply the experience accumulated over four years in the University for overseas practice and promote the unity of knowing and doing.

\section{Acknowledgements}

This research was financially supported by the Project of Undergraduate Teaching Reform of Higher Education in Guangxi in 2015, in which the content was Research of Practice of Overseas Chinese Education based on Training System Integration in International Chinese Education Specialty (Grant No. 2015JGB225).

\section{References}

[1]. Liu Xun. Introduction to Teaching Chinese as a Foreign Language Pedagogy. Beijing Language and Culture University Press, 2000.

[2]. Lu Jianming. The quality of Chinese Teachers: Discussion on the Training and Cultivation of Chinese Teachers. Chinese Language Globalization Studies. 2013, 18-19.

[3]. Wu Huaicheng. Discussion on Practice Issues of Teaching Chinese to Speakers of Other Languages Undergraduates. Journal of Language and Literature Studies. 2016, (5): 31-33.

[4]. $\mathrm{Xu}$ Wei. Research on the Teachers ' Classroom Questions of in the Primary Stage of Teaching Chinese as a Foreign Language. Jinan University. 2007, (16): 42-43.

[5]. Xu Ziliang. Psychology of Teaching Chinese as a Foreign Language. East China Normal University Press, 2007. 